\title{
Review \\ B cells in Sjögren's syndrome: indications for disturbed selection and differentiation in ectopic lymphoid tissue
}

\author{
Arne Hansen ${ }^{1}$, Peter E Lipsky² and Thomas Dörner ${ }^{1}$
}

\author{
${ }^{1}$ Charite Centers (CC) 12 and 14, Departments of Medicine and Transfusion Medicine, Charité-Universitätsmedizin Berlin, Charité-Platz 01, \\ 10098 Berlin, Germany \\ ${ }^{2}$ Autoimmunity Branch, National Institute of Arthritis and Musculoskeletal and Skin Diseases, National Institutes of Health, Building 10, Bethesda, \\ MD 20892, USA
}

Corresponding author: Arne Hansen, arne.hansen@charite.de

Published: 6 August 2007

This article is online at http://arthritis-research.com/content/9/4/218

(c) 2007 BioMed Central Ltd
Arthritis Research \& Therapy 2007, 9:218 (doi:10.1186/ar2210)

been termed 'autoimmune exocrinopathy' [1] or 'autoimmune epithelitis' [4]. Focal infiltrates [5,6] of T and B lymphocytes, dendritic cells (DCs) and macrophages [7-10] with subsequent impairment of the salivary and lacrimal glandular function are hallmarks of the disease and result clinically in xerostomia and keratoconjunctivitis sicca. In addition to the (glandular) organ-specific manifestations, there is a wide range of accompanying clinical and laboratory manifestations, emphasizing that pSS is a systemic autoimmune disorder [1-4].

The origin of pSS remains largely unknown. As with other complex multigenic and multifactorial autoimmune diseases, several infectious environmental factors, especially viral agents such as Epstein-Barr virus, non-human immunodeficiency retroviruses and, more recently, coxsackieviruses (namely the CVB4 and CVA13 strains) have been postulated to be involved in priming or triggering pSS [11-14], on the basis of a distinct genetic and hormonal background [1-3,15]. Disturbed clearance from salivary gland epithelial cells (SGECs) $[5,16]$ may lead to glandular persistence of viruses and to repeated lymphocytic sialadenitis with chronic immune system stimulation [17]. However, it remains to be determined whether viral infection of the affected glands is primary or secondary to the development of autoimmunity in pSS (for example Epstein-Barr virus infection [18]) or whether different viruses (for example HTLV-1 [13], CVB4 and CVA13 [14]) may act as endemic triggers in distinct human populations.

Although the process that underlies the cellular and humoral autoimmune response in pSS is not known, it is well established that both $\mathrm{T}$ and $\mathrm{B}$ lymphocytes are involved and

$\mathrm{APRIL}=$ a proliferation-inducing ligand; $\mathrm{BAFF}=\mathrm{B}$-cell activating factor; $\mathrm{BCR}=\mathrm{B}$-cell receptor; $\mathrm{DC}=$ dendritic cell; $\mathrm{GC}=\mathrm{germinal}$ center; ${ }_{\mathrm{H}} \mathrm{CDR} 3=$

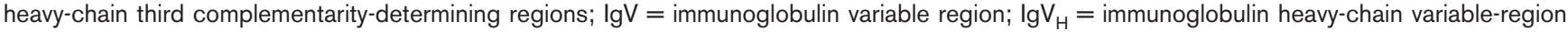
gene; IL = interleukin; MZ = marginal zone; pSS = primary Sjögren's syndrome; RA = rheumatoid arthritis; RF = rheumatoid factor; SGEC = salivary gland epithelial cell; SLE = systemic lupus erythematosus; $S S=$ Sjögren's syndrome; $\mathrm{TACl}=$ transmembrane activator and CAML interactor; $\mathrm{TNF}=$ tumor necrosis factor. 
that interactions of activated SGECs and endothelial cells with the infiltrating lymphoid and dendritic cells contribute to the perpetuation and progression of the disease as well as to systemic lymphocyte derangements [1-4]. In this context, dysregulation of the Th1/Th2 balance and chronic B-cell hyperactivity are consistent and prominent immunoregulatory abnormalities in pSS [1-3,19,20].

Characteristic features indicating B-cell disturbances in pSS include circulating immune complexes, hypergammaglobulinemia, occurrence of organ-specific and organ nonspecific autoantibodies (for example those against the Ro-SSA and/or La-SSB autoantigens and rheumatoid factors), characteristic disturbances of peripheral B-cell subsets, formation of ectopic lymphoid tissue with germinal center (GC)-like structures, oligoclonal B-cell proliferations and, finally, the enhanced risk of developing B-cell lymphoma [1-3,21].

Recent studies [22-35] have broadened our understanding of $\mathrm{B}$-cell involvement in pSS by indicating that humoral markers of B-cell hyperactivity and peripheral B-cell derangement partly mirror the processes in the inflamed tissues, especially in patients with pSS with detectable ectopic GC-like structures. Similarly to pSS [27-35], ectopic lymphoid structures have also been described in the target tissues of several other autoimmune and non-autoimmune conditions that are accompanied by B-cell disturbances and/or enhanced lymphoma risk, for example rheumatoid arthritis (RA) [21,36], systemic lupus erythematosus (SLE) [21,37], autoimmune thyroiditis [38,39] and chronic infections such as those by human immunodeficiency virus (HIV) [40,41], hepatitis C virus [42,43] and Helicobacter pylori [44]. Delineation of common and diverse mechanisms that underlie the B-cell disturbances and development of ectopic GC-like structures in these disease entities should be important for our understanding of their immunopathogenesis. Moreover, this may also provide new strategies for B-cell-targeted therapies in pSS, a disease with inadequate conventional therapy. Taking current data as a basis, this review focuses on the possible role of ectopically formed lymphoid tissue, including GC-like structures, in B-cell disturbances and autoimmune response in patients with pSS.

\section{Lymphocytic sialadenitis and formation of ectopic germinal-center-like structures}

Chronic focal periductal lymphocytic sialadenitis is a hallmark of pSS $[5,6]$ and it has therefore been included in the classification criteria of the disease $[45,46]$. Although sequential analyses starting from early glandular tissue infiltrates in pSS are not available, lymphocytic sialadenitis in pSS is generally thought to be a stepwise process [1-4]. This process may include a sequence of scattered tiny perivascular lymphoid infiltrates, subsequent development of the typical focal periductal lymphoid sialadenitis/formation of ectopic GC-like structures and, eventually, the destruction and replacement of the affected glandular tissue [8,27-35].
Notably, cytokine-mediate and/or autoantibody-mediated neuroendocrine glandular tissue dysfunction may occur before glandular tissue damage is histologically evident $[47,48]$.

The lymphoid tissue infiltrates in pSS contain T cells, B cells and plasma cells, with a predominance of primed $\mathrm{CD}^{+}{ }^{+}\left(\mathrm{CD} 45 \mathrm{RO}^{+}\right) \mathrm{T}$ cells in early-stage disease [7-9]. It is noteworthy that SEGCs are suggested to have a distinct intrinsic or virus-activated status with disturbed apoptosis as well as with the capability of promoting cell adhesion, to function as antigen-presenting cells, and to co-stimulate infiltrating $\mathrm{CD}^{+} \mathrm{T}$ cells $[5,49]$. Proinflammatory cytokines (produced, for example, by the infiltrating CD4 ${ }^{+} \mathrm{T}$ cells and dendritic cells) such as interferon- $\gamma, \mathrm{IL}-1 \beta$ and TNF seem to enhance the activation status of the SEGCs in a positive feedback loop [5,50]. Activated SGECs may also express CD40 protein, a molecule associated with B-cell and DC activation [51,52], as well as B-cell activating factor (BAFF) [53,54] and B-cell-attracting chemokines [29-31]. Moreover, infiltrating CD4 ${ }^{+} \mathrm{T}$ cells and DCs may also locally produce a broad variety of B-cell-targeted cytokines and survival factors, including BAFF and APRIL (a proliferation-inducing ligand) $[50,55]$. Thus, a tight interplay between activated SGECs, infiltrating lymphocytes and DCs leads to the perpetuation and progression of the disease, in an auto-amplifying loop.

B cells comprise about $20 \%$ of the lymphoid minor (labial) salivary gland infiltrates in early-stage disease [7-9], but higher degrees of lymphoid organization are associated with progressive increases in the proportion of B cells and T-cell/Bcell segregation, especially during the formation of ectopic GC-like structures [27-33]. These ectopic 'tertiary' GC-like structures of the inflamed tissues bear a histological resemblance to the GCs of secondary lymphoid organs. They contain T-cell and B-cell aggregates with proliferating lymphocytes, a network of follicular DCs, and activated endothelial cells with the morphology of high endothelial venules [37-33]. In healthy individuals, GCs are generated from primary B-cell follicles of secondary lymphoid organs during T-celldependent immune responses [56]. Lymphoid neogenesis with or without the formation of ectopic GC-like structures in chronic inflammatory diseases, such as pSS and RA, is a complex process regulated by an array of cytokines, adhesion molecules and chemokines, partly mimicking signals found in normal lymphoid organogenesis [27-34,57-60]. However, despite similarities to GCs of secondary lymphoid organs, the function and potential pathogenetic role of ectopically formed lymphoid structures within inflamed tissues remain unclear.

For example, in pSS, the following open questions remain about the role of ectopically formed lymphoid tissue in B-cell disturbances and autoimmune response: (1) Does the formation of ectopic GC-like structures characterize a distinct subgroup of patients? (2) Is the (auto)immune B-cell response in ectopic lymphoid tissues dominated by $\mathrm{T}$-celldependent or T-cell-independent pathways? (3) Does ectopic 
lymphoid tissue represent the main priming site of autoreactive $B$ cells? (4) Does ectopic lymphoid tissue formation contribute to characteristic peripheral B-cell disturbances caused by the underlying disease?

\section{Diagnostic salivary gland biopsies detect ectopic germinal center formation}

Three distinct types of lymphoid microarchitecture can be identified within the inflamed glands in pSS: unorganized diffuse infiltrates, focal periductal T-cell and B-cell aggregates lacking GC characteristics, and ectopic GC-like structures [5,10,27-34]. Ectopic GC formation is associated with a higher degree of lymphoid sialadenitis - that is, with a higher focus score $[6,33]$ - and GC-like structures often coincide with focal periductal infiltrates [33]. Importantly, detection of GC-like structures depends on the size or area of the analyzed specimen [1]. At the time point of diagnostic biopsy of the minor submucosal (labial) salivary glands, GC-like structures have been documented in up to one-quarter of patients with pSS [32,33]. By conventional routine histological staining, for example with hematoxylin/eosin on paraffin-embedded material, GC-like structures differ from focal periductal infiltrates of mononuclear cells in having a higher degree of lymphoid organization with a dark-appearing mantle of densely packed cells and a lighter-appearing center. Immunophenotyping reveals further characteristics of well-ordered B cells, T cells, a network of follicular DCs and activated endothelial cells in these ectopic GCs [27-34] and, moreover, enhances the sensitivity of their detection [33].

However, it should be kept in mind that the time frame from disease onset to diagnostic salivary gland biopsy may vary markedly between different patients [2]. In this context, it remains to be further elucidated whether the detection of ectopic GC-like structures in a single biopsy reflects a snapshot of a slowly progressive inflammatory disease, pSS, or a subpopulation of patients with a more severe disease and/or a distinct immune response. Recent studies have shown a positive correlation between a high degree of lymphoid tissue infiltration/ectopic GC formation in the minor (labial) salivary glands and both the occurrence of autoantibodies [32,61,62] and hypergammaglobulinemia (elevated lgG levels) [33]. Moreover, a high degree of lymphoid tissue infiltration or ectopic GC formation may be related to an increased risk of extraglandular manifestations and lymphoma [62-65]. At least, the detection of GC-like structures in minor (labial) salivary gland biopsies may reflect a progressive stage of disease in a distinct subset of patients.

The proportion of 'ectopic GC-like structure-positive' patients with pSS may be somewhat underestimated by a single biopsy of the minor (labial) salivary glands. In addition, minor (labial) salivary glands are the most frequently investigated but not the only tissue investigated for lymphocytic lesions in pSS $[66,67]$. Importantly, the nature and intensity of immune responses may vary between different affected tissues, for example between different types of exocrine gland [66]. In patients with pSS and recurrent or persistent swelling of the major salivary glands, the lymphocytic lesions of the involved glands often contain massive lymphoid infiltrates with secondary lymph follicles and/or intraglandular lymph nodes $[63,64]$. In this context, a recent study has documented a strong correlation between the degree of lymphoid tissue infiltration or formation of ectopic GC-like structures within biopsies of the minor (labial) and major (parotid) glands of patients with pSS [67]. Thus, the pattern of lymphoid infiltrates of minor submucosal (labial) salivary glands seems to be a marker of general inflammatory tissue involvement in pSS, although further elucidation will be necessary to determine whether the underlying immune processes may vary between different types of inflamed tissue.

\section{Characteristic distribution of peripheral B-cell subsets}

From the available data on the distribution of B-cell subsets in chronic inflammatory rheumatic diseases, such as pSS, RA and SLE, and in infectious diseases, there is increasing evidence that diseases associated with immunological hyperactivity can be characterized by unique features of $B$ cell subset distribution $[68,69]$. Thus, the circulating B-cell repertoire in peripheral blood may partly reflect complex influences on differentiation, activation, selection, homing and recirculation of $B$ cells from a variety of immune compartments, including the inflamed target tissues.

In this regard, the identification of CD27 as a marker of memory $B$ cells [70] and plasmablasts [71] made it possible to characterize peripheral $\mathrm{CD} 27^{-}$naive, $\mathrm{CD} 27^{+}$memory $\mathrm{B}$ cells and CD27high plasmablasts/plasma cells. Interaction of CD27 with its ligand on T cells, CD70, serves as a pathway of differentiation of $B$ cells into plasma cells $[71,72]$. Recently, homotypic interaction of CD27 and CD70 expressed by $B$ cells was also reported to be sufficient for $B$ cell differentiation, raising the possibility that $B$ cells may be able to regulate themselves by CD27-CD70 interactions [72]. Analysis by various groups $[22,24,70,71]$ indicates that $\mathrm{CD}^{-} 7^{-}$naive, $\mathrm{CD}^{+} 7^{+}$memory $\mathrm{B}$ cells and CD27 high plasmablasts/plasma cells exist in relatively stable relations in the peripheral blood of healthy adults, although the frequency of $\mathrm{CD} 27^{+}$memory $\mathrm{B}$ cells reflects the accumulation of antigen experience of an individual that is, at least in part, dependent on age [71]. In accordance, cord blood normally does not contain CD27+ $\mathrm{B}$ cells [73]. In healthy adults, CD27- naive B cells, CD27+ memory B cells and CD27high plasmablasts/plasma cells comprise about $70 \%, 30 \%$ and $1 \%$, respectively, of all CD19+ B cells in peripheral blood. An increase in peripheral CD27high plasmablasts/plasma cells has been shown after vaccination with bacterial antigens in healthy individuals [74].

In pSS, immunophenotyping studies indicate characteristic disturbances in the distribution of peripheral B-cell subsets, 
with a predominance of CD27- naive B cells and diminished frequencies and absolute numbers of CD2 $7^{+}$memory $B$ cells [22-24], especially of the $\mathrm{CD}^{2} 7^{+} / \mathrm{lgM}^{+}, \mathrm{CD} 27^{+} / \mathrm{lgD}^{+}$and $\mathrm{CD}^{2} 7^{+} / \mathrm{CD}^{+}$memory B-cell subsets [24]. These findings clearly contrast with the pattern of $B$ cells in peripheral blood in healthy adults but also in patients with autoimmune disorders that have to be distinguished from pSS such as SLE, RA and secondary Sjögren's syndrome (SS) [68,69]. In comparison with either healthy subjects or patients with pSS, patients with SLE have increased numbers of circulating $\mathrm{CD}^{2} 7^{+}$memory B cells, reduced numbers of CD27- naive $B$ cells, and markedly increased numbers of CD27 high plasma cells that seemed to be related to lupus disease activity and/or immunosuppressive therapy $[75,76]$. In contrast to patients with pSS or RA, patients with SLE are frequently B-cell lymphopenic [69]. Patients with RA show a similar distribution of peripheral CD27- naive $B$ cells and CD27+ memory B cells but a significantly enhanced $C D 27^{+} / \lg D^{+}$ memory subpopulation when compared with healthy donors and patients with pSS $[22,69]$. The distribution of peripheral B-cell subsets in patients with secondary SS are, at least, dominated by those of the associated rheumatic disorder, for example RA or SLE. Thus, the disturbances of the B-cell subsets seem to be unique for each of the respective diseases [68].

It is of potential interest that the status of the peripheral B-cell subset distribution seems similar between pSS and HIVinfected patients with predominantly $C D 27^{-}$naive $B$ cells $[41,68]$. In this context, CD4 ${ }^{+} \mathrm{T}$ cells are progressively depleted in HIV infection, and patients with pSS often show a mild CD4 ${ }^{+} \mathrm{T}$ lymphopenia. One interpretation of these observations may be that $\mathrm{T}$-cell-dependent priming of $\mathrm{B}$ cells may occur to a smaller degree in patients with pSS than in healthy individuals and, especially, than in patients with SLE. In contrast, diminished numbers of $\mathrm{CD}^{+} \mathrm{T}$ cells in peripheral blood are found especially in patients with pSS showing Ro/SSA positivity [77] and may reflect trafficking of primed $\mathrm{CD}^{+} \mathrm{T}$ cells into the inflamed glands or GC-like structures with subsequent autoantibody production [9,32]. Altered Bcell differentiation and priming, shedding of surface CD27 molecules, accumulation of $\mathrm{CD}^{2} 7^{+}$memory $\mathrm{B}$ cells in inflamed tissues and altered recirculation of B-cell subsets from these sites may all contribute to disturbed B-cell homeostasis in pSS [22-24].

\section{Chemokines, ectopic germinal center formation and accumulation of memory $B$ cells}

Support for the hypothesis that the decrease in $\mathrm{CD}_{2}{ }^{+}$ memory B cells in peripheral blood that occurs in pSS may be partly related to their accumulation in the affected exocrine glands comes from the combined immunophenotypic and molecular studies analyzing B cells in peripheral blood and salivary glands of patients with pSS [22-24,78]. These studies revealed a polyclonal accumulation of $\mathrm{CD}^{2} 7^{+}$ memory $B$ cells and CD27high plasma cells in the inflamed tissues, despite evidence of some clonally expanded B cells. In more detail, peripheral blood B cells and glandular B cells in patients with pSS used a similar polyclonal repertoire of rearrangements of the immunoglobulin heavy-chain variableregion gene $\left(\operatorname{lgV}_{\mathrm{H}}\right)$ [24,78]. However, when compared with their peripheral blood counterparts, the vast majority of glandular $B$ cells expressed heavily mutated $\operatorname{lgV}_{\mathrm{H}}$ rearrangements [24] along with significantly shorter heavychain third complementarity-determining regions ${ }_{H} \mathrm{CDR} 3$ ) and a less frequent usage of the sixth heavy-chain joining segment $\left(\mathrm{J}_{\mathrm{H}} 6\right)$ [79], emphasizing the accumulation of memory $B$ cells. Thereby, enhanced influx and retention of particular polyclonal memory $B$ cells into the inflamed glands have been suggested in patients with pSS, rather than the proliferation of a few founder B cells entering the parotid GC-like structures [24]. Notably, clonally related B cells have been detected in the peripheral blood and the inflamed parotid gland of a patient with pSS $[79,80]$.

In addition, accumulation of memory B cells in the inflamed salivary glands has been indicated by the analysis of chemokine receptor-ligand interactions in pSS [26]. Interactions of chemokines with their corresponding chemokine receptors have been identified as having an important role in lymphopoiesis, differentiation, homing, recirculation and immune responses of lymphocytes under physiological and pathological conditions, such as chronic inflammation and ectopic GC formation [26,28-31,57-60]. The chemokinechemokine receptor pairs CXCL13 (BCA-1)-CXCR5 and CXCL12 (SDF-1)-CXCR4 have been shown to be critically involved in the homing of B cells to lymphoid follicles and in the development of organized lymphoid follicles in healthy individuals [60]. Mice deficient in the lymphoid-homing chemokine receptors CXCR4 and CXCR5 lack normal lymphoid organs $[60,81]$. In addition, studies in CXCL13 transgenic mice found that this chemokine, together with TNF and lymphotoxin- $\beta$, is crucial in lymphoid organogenesis, whereas the lymphotoxin- $\beta$ 'knockout mouse' lacks the formation of lymphoid structures $[59,60]$. Studies on RA demonstrated that CXCL12 and CXCL13 [57-59] are also involved in the formation of GC-like structures in the rheumatoid synovium.

In pSS, recent studies reported that CXCL9 (Mig), CXCL10 (IP-10), CXCL12 (SDF-1), CXCL13 (BCA-1), CCL18 (PARC), CCL19 (ELC) and CCL21 (SLC) may all contribute to lymphoid homing and the persistence of chronic inflammation [28-31,59,60]. However, when compared with the inflammatory process of nonspecific sialadenitis, salivary glands in patients with pSS have been found to express a unique profile of adhesion molecules, cytokines and chemokines including a striking overexpression of the B-cellattracting chemokine CXCL13 (BCA-1) and, to a smaller degree, CXCL12 (SDF-1) [28-31]. Accordingly, B cells expressing the corresponding receptors for $\mathrm{CXCL} 13$ (BCA-1) and CXCL2 (SDF-1), CXCR5 and CXCR4, 
respectively, have been detected in the glandular infiltrates of patients with pSS [26,28,30]. Moreover, differential expression of the chemokine receptors CXCR4 and CXCR5 but not of CXCR3, CCR6, CCR7 and CCR9 has been found on peripheral blood $B$ cells of patients with pSS in comparison with those from healthy donors [26]. Thus, CXCL12-CXCR4 and CXCL13-CXCR5 interactions have been strongly suggested to be of special importance in B-cell disturbances in pSS and may be closely associated with the entire inflammatory process, the development of ectopic GClike structures as well as with peripheral B-cell disturbances [26,28-31]. Overexpression of CXCL13 in inflamed glands with consequent local retention of CXCR5-bearing $B$ cells $[28,30]$ might also lead to reduced frequencies of peripheral CD27+ memory B cells expressing lower levels of surface CXCR5 than peripheral B cells of healthy donors [26]. Consistent with this, the vast majority of infiltrating CD27+ memory $\mathrm{B}$ cells in pSS salivary glands co-express CXCR5 with CXCR4, whereas there is a striking decrease in CXCR4 ${ }^{+} \mathrm{CXCR} 5{ }^{+}$double-positive $\mathrm{CD}^{2} 7^{+}$memory $\mathrm{B}$ cells but not CXCR4 ${ }^{+} \mathrm{CXCR} 5^{+}$double-positive naive $\mathrm{B}$ cells in the peripheral blood of patients with pSS [26]. In this context, both in healthy individuals and in patients with pSS, CD27+ memory $\mathrm{B}$ cells show a higher intrinsic transmigratory capacity to CXCL12 and CXCL13 than CD27- naive B cells [26]. Thus, glandular coexpression of both CXCL12 and CXCL13 [28-31] seems to direct this subpopulation of peripheral $\mathrm{CD} 27^{+}$memory $\mathrm{B}$ cells preferentially into the inflamed glands where it resides. Consistent with this, residual circulating peripheral $\mathrm{CD} 27^{+}$memory $\mathrm{B}$ cells of patients with pSS showed a diminished migratory response to the corresponding ligands of CXCR4 and CXCR5, namely CXCL12 and CXCL13, respectively [26]. This suggests that memory $B$ cells with less migratory capacity remain in the blood as a result of the selective migration and retention of CXCR4 ${ }^{+} \mathrm{CXCR}^{+}$memory $\mathrm{B}$ cells into the inflamed glands and thereby supports recent immunophenotypic and molecular studies in pSS, indicating a preferential accumulation of memory $B$ cells in the salivary gland infiltrates $[24,79]$.

\section{Autoantibody responses, autoreactive B cells and ectopic germinal centers}

The production and persistence of autoantibodies in autoimmune conditions are considered to occur because of immune dysregulation with a resultant break in tolerance [82]. Despite intensive work on the characterization of autoantigens, B-cell biology, the cellular basis of autoantibody production, the role of cytokines and chemokines, autoantibody-encoding immunoglobulin variable region ( $\operatorname{lgV}$ ) genes and associations of certain autoantibody specificities with particular MHC class II alleles, our understanding about the origin and potential pathogenetic role of most of the autoantibodies is still very limited.

However, autoantibodies in the patient's serum and/or saliva are a key manifestation of B-cell hyperactivity in pSS [1-3,
83,84]. Various autoantibody specificities have been reported in patients with pSS, including antibodies against ubiquitous or organ-nonspecific autoantigens (for example Ro/SSA, $\mathrm{La} / \mathrm{SSB}, \alpha$-Fodrin and the Fc fragment of $\lg \mathrm{G}$ ) and to mostly organ-specific autoantigens (for example muscarinic M3 receptor and islet cell antigen 69) [1-3]. However, only a few of them, such as anti-muscarinic M3 receptor antibodies, have been implicated in contributing directly to the impairment of salivary gland function in patients with pSS [47]. It is more likely that most of these autoantibodies occur in response to glandular tissue damage, apoptosis and/or the expression of neoantigens such as cleaved La/SSB [85] and Ro/SSA-hYRNA complexes on the blebs of apoptotic glandular cells [86]. In this regard, $52 \mathrm{kDa}$ Ro/SSA has recently been characterized to function as an E3 ligase that regulates proliferation and cell death and may thereby contribute to the autoantigen load and induction of immune responses in rheumatic disorders when there is increased 52 kDa Ro/SSA expression [87].

Altogether, the detection of both autoantigen-specific $\mathrm{T}$ and $B$ cells $[88,89]$, evidence of antigen-driven clonal B-cell expansions by analyzing the mutations of $\mathrm{lgV}$ gene rearrangements [27], a linkage between local autoantibody production and ectopic GC development [30,32] and the occurrence of class-switched autoantibodies in the patient's saliva [84] all strongly indicate that T-cell-dependent immune responses may occur to some extent in lymphoid tissue infiltrates, especially in those containing ectopic GC-like structures. In addition, the formation of autoantibodies in pSS seems to occur independently from such structures, because circulating autoantibodies are much more frequent than ectopic 'tertiary' GCs in patients with pSS [32,33,67].

Of potential importance is a more recent study [35] that has also claimed to detect marginal-zone (MZ)-like B cells within the lymphoid tissue infiltrates of minor salivary glands of patients with pSS. It is known that both hypermutation and $\mathrm{lg}$ class switch can also be mediated by $\mathrm{T}$-cell-independent pathways [90,91]. Hence, T-cell-independent immune responses may also occur within the inflamed tissues in pSS. In this context, immune complexes, such as those containing locally produced anti-Ro/SSA and nucleoprotein, may activate dendritic and other cell types via $\mathrm{Fc}-\gamma$ receptors, Tolllike receptors or B-cell receptors (BCRs) with rheumatoid factor (RF) activity [92,93].

RF-expressing B cells seem to be intimately involved in the pathogenesis of pSS, as has been indicated by the combined results of several serological, molecular and epidemiological studies [1,80,93-95]. Moreover, the subpopulation of RFexpressing MZ-like B cells seems to be closely related to lymphoma development in pSS [96-101]. Because MZ $B$ cells have been shown to be selected against autoreactivity in healthy normals [102], the persistence of RF-expressing, that is self-reactive, MZ-like $B$ cells in pSS may reflect a 
disturbed selection within the 'niche' of ectopically formed lymphoid tissue that might permit the escape of MZ-like $B$ cells from BCR-mediated apoptosis, a normal physiological peripheral 'checkpoint' against autoreactivity in secondary lymphoid organs. In addition, the local production of $\operatorname{lgG}$ immune complexes, for example of anti-Ro/SSA-nucleoprotein complexes, may contribute to chronic activation and proliferation of MZ-like B cells and, finally, to enhanced risk for lymphoma development.

In this regard, BAFF and APRIL, two important factors that can promote B-cell survival, have been strongly suggested to be involved in both local and systemic autoimmunity in pSS, including T-cell-independent immune responses [103,104]. Moreover, excess BAFF has been shown to be a potent survival factor for mature B-cell malignancies [103]. Thus, enhanced levels of BAFF have been demonstrated in diseases such as pSS, SLE and RA, which are associated with abnormal B-cell function and autoantibody production. In particular, the highest BAFF levels have been found in patients with pSS [53]. A recent study has shown a clear anti-apoptotic effect of BAFF on B cells in peripheral blood from patients with pSS that might lead to prolonged B-cell survival in pSS [105]. Moreover, local expression of BAFF has been found to be markedly enhanced in the inflamed salivary glands in pSS. Locally expressed BAFF, for example by glandular epithelial cells [54] and/or infiltrating T cells and macrophages [55], may induce the accumulation of selfreactive $B$ cells by providing help to escape from BCRengaged apoptosis. Thus, local BAFF expression may be central in the progression of the entire autoimmune process by triggering B-cell survival and autoantibody production $[103,106]$. Positive correlations between serum levels of BAFF and APRIL with both the focus score of salivary glands and serum IgG levels, especially in anti-Ro/anti-La-positive patients, further suggest a possible role for BAFF and APRIL in B-cell hyperactivity in pSS [33,34]. It is of potential importance that BAFF together with BCR engagement seems to be intimately involved in T-cell-independent B-cell activation, including $\mathrm{lg}$ class switch recombination via transmembrane activator and CAML interactor (TACI), one of the receptors for BAFF and APRIL [103,104]. Consistent with this, studies in BAFF-transgenic mice revealed an expansion of the MZ B-cell population and enhanced T-cellindependent immune responses [107]. Although the degree of T-cell-independent immune response in pSS remains unclear, taken together these studies strongly suggest an important role of BAFF excess in B-cell disturbances, autoantibody production and possibly B-cell lymphomagenesis [103].

Autoantibody production may perpetuate the entire inflammatory process as well as serving as an indicator of immune dysregulation. Thus, autoantibodies in pSS also seem to represent markers of disease progression and to characterize a proportion of patients who are susceptible to a more systemic involvement [108]. In patients with pSS, the occurrence of circulating autoantibodies against the Ro/SSA and La/SSB autoantigens, as well as elevated RF levels, is correlated with the progressive stage of sialadenitis/formation of ectopic lymphoid structures, systemic manifestations and/or enhanced lymphoma risk $[61,62,65,101,108]$. However, because stable levels of autoantibodies in serum are also found in patients with pSS with late-stage disease, namely with mostly atrophic exocrine glands, the generation of longlived plasma cells [109] or alternative sites for the ongoing stimulation of autoreactive B cells in pSS may occur. In this context, in addition to the salivary glands, autoreactive/ autoantibody-producing cells may also reside in 'true' lymphoid tissues of the secondary lymphoid organs and the bone marrow, as demonstrated in the lymph nodes of seropositive MRL//pr mice [110].

\section{$\lg V_{H / L}$ analyses indicate disturbed B-cell selection in ectopic lymphoid tissues}

As has been reviewed elsewhere [68], recent analyses have provided no clear indication for inherited abnormalities in $\lg V_{H}$, $V_{\kappa}$ and $V \lambda$ gene usage in patients with pSS in comparison with healthy individuals. The most striking abnormalities found in these studies were related to influences of selection; that is, post-recombination processes. In B cells in peripheral blood, the abnormalities included $V_{L}$ gene distribution of four $V \lambda$ genes (2A2, 2B2, $2 \mathrm{C}$ and $7 \mathrm{~A}$ ), representing $56 \%$ of all functional $V \lambda$ light chain rearrangements [111], and three $V_{\kappa}$ genes (L12, O12/O2 and B3) comprising 43\% of all functional $\mathrm{V} \kappa \mathrm{K} \kappa$ rearrangements [112]. In contrast, there were also specific differences in the $V_{L}$ gene repertoire when $B$ cells from blood and from the parotid gland were compared [80]. B cells from the parotid gland have been identified as a distinct population showing accumulation, expansion and somatic mutation of particular $V_{L}$ chain rearrangements, such as

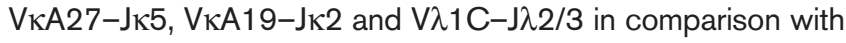
peripheral $B$ cells [80]. Together, these data are consistent with the conclusion that positive selective processes and clonal expansions shape a distinct $\mathrm{V}_{\mathrm{L}}$ gene repertoire of $\mathrm{B}$ cells accumulated within the inflamed gland. Although the corresponding $\mathrm{V}_{\mathrm{H}}$ repertoire was similar in the blood and in the parotid, this analysis detected glandular accumulation of memory $B$ cells with significantly enhanced mutational frequencies and shorter third ${ }_{H}$ CDRs than their counterparts in peripheral blood [24,79]. Collectively, this data set of $\mathrm{V}_{\mathrm{H} / \mathrm{L}}$ gene usage indicates positive selection and accumulation of memory $\mathrm{B}$ cells expressing particular $\mathrm{V}_{\mathrm{L}}$ genes within the ectopic lymphoid tissue in pSS $[24,79,80]$. In accord with these results, earlier studies examining idiotype expression by glandular B cells in pSS have also suggested that these cells represent a selected population. B cells expressing RFassociated cross-reactive idiotypes, in particular the light-chain idiotype 17.109 (encoded by the VКA27/humkv325 gene) and to a smaller degree the heavy-chain idiotypes G6, G8 and H1 (encoded by the $\mathrm{V}_{\mathrm{H}}$ 1-69/DP-10 gene), are increased in the salivary gland infiltrates of patients with pSS compared with those with nonspecific sialadenitis [94,95]. 
Finally, it is well established that patients with pSS are at higher risk to develop B-cell non-Hodgkin lymphomas [21], which emerge frequently within ectopic lymphoid tissues or corresponding lymph nodes of the organs targeted by pSS [64,96-101]. These lymphomas, frequently extranodal $M Z$ B-cell lymphomas [96-101], use remarkedly biased $\lg \mathrm{V}_{\mathrm{H} / \mathrm{L}}$ gene repertoires with distinctive features of the third ${ }_{H} \mathrm{CDR}$ that may often encode rheumatoid factors [96-98]. A recent study [97] provided direct evidence that two cases of IgMKexpressing parotid gland B-cell non-Hodgkin lymphomas, namely a small lymphocytic lymphoma and a $M Z$ B-cell lymphoma, developed in patients with pSS from monospecific RF-expressing B cells. More recently, (re)circulation of two additional parotid gland B-cell clones along with the lymphoma clone, all expressing RF-associated $\mathrm{V}_{\mathrm{H} / \mathrm{L}}$ rearrangements, have been found in a patient with pSS with extranodal $\mathrm{MZ}$ B-cell lymphoma of the parotid gland [98]. Ongoing $\mathrm{V}_{\mathrm{H} / \mathrm{L}}$ mutations with an (auto)antigen-selected pattern in extranodal MZ B-cell lymphomas in pSS strongly suggest that both genesis and progression of these lymphomas are (auto)antigenselected processes $[96,98,113]$. Taken together, these data implicate disturbed selection and (auto)antigen stimulation of $B$ cells within the ectopic lymphoid tissues in pSS that may eventually contribute to the enhanced risk for lymphoma in these patients [21].

\section{(Re)circulating peripheral B cells exhibit signs of abnormal differentiation}

Amplification of mRNA by single-cell analysis allows the evaluation of the transcriptome of individual cells and therefore provides the opportunity to gain an insight into the variability of immunocompetent cells. By employing this approach on $\lg \mathrm{V}_{\mathrm{H}}$ expression and additional target mRNAs in peripheral CD27- and CD27+ $B$ cells from patients with pSS [25], several abnormalities became apparent. Although the distribution of $\mathrm{V}_{\mathrm{H}}$ and $\mathrm{J}_{\mathrm{H}}$ family members, the usage of individual $V_{H}$ segments and the ${ }_{H}$ CDR3 length were very similar between healthy controls and patients with pSS, markedly enhanced percentages of $\operatorname{lgV}_{H}$ mRNA-positive $B$ cells were found in patients with pSS [25]. This difference may reflect polyclonal B-cell hyperactivity [1-4] with increased Ig mRNA levels in pSS, because mRNA expression of housekeeping genes was comparable between patients and controls by this analysis [25]. In addition, several abnormalities suggest disturbed or incomplete B-cell differentiation processes in pSS that contrast with the findings in healthy subjects.

First, CD27- B cells from patients with pSS included a notable proportion (about 17\%) of memory-like B cells that expressed $\operatorname{lgV}_{\mathrm{H}}$ rearrangements with two or more mutations per $V_{H}$ segment [25]. The frequency of such CD27- memorytype $B$ cells detected at the single-cell mRNA level was in line with previous genomic single-cell studies in patients with pSS [24], whereas these cells occur infrequently among CD27- B cells of healthy subjects [70]. CD27- memory-type
B cells may represent recirculating cells from secondary or ectopically formed 'tertiary' lymphoid tissues with low-level, transiently expressed or shed CD27 surface molecules. In this regard, recent studies of patients with pSS have suggested abnormal B-cell differentiation and activation characterized by depressed percentages of circulating CD27+ memory B cells [22-24], enhanced serum IgG levels and elevated levels of soluble CD27 [23]. It is currently unknown whether enhanced frequencies of (re)circulating CD27- memory-like B cells are correlated with a higher degree of tissue involvement or ectopic GC formation. However, it should be noted that the mutational frequencies of $\mathrm{CD}^{2} 7^{-} \mathrm{B}$-cell-derived mutated $\operatorname{lgV}_{\mathrm{H}}$ rearrangements in pSS were significantly lower than that of their CD27+ memory B-cell-derived counterparts [24,25]. This may possibly reflect $\mathrm{T}$-cell-independent B-cell activation [90,91], for example via Toll-like receptors and/or BAFF-TACl interaction [92,104].

Second, the peripheral CD27+ memory B-cell-derived $\lg \mathrm{V}_{\mathrm{H}}$ transcripts from patients with pSS differed from those in healthy controls in having significantly enhanced mutational frequencies, including an abnormal isotype-specific order in mutational frequencies [25]. In particular, in patients with pSS, the CD27+ memory B-cell-derived $\mathrm{c} \mu$ transcripts were found to be significantly more mutated than the corresponding $\gamma$ and $\alpha$ chain transcripts. If these findings are combined with those from previous immunophenotyping and molecular studies [24,80,94-98], the populations of $\operatorname{lgM}(\mathrm{c} \mu)$ expressing memory $B$ cells and memory-type $B$ cells seem to be closely involved in both B-cell disturbances and malignant complications in pSS.

Finally, more than half of individual peripheral CD27+ memory $B$ cells from patients with pSS have been found to express spliced $\lg \mathrm{V}_{\mathrm{H}}$ mRNA transcripts of more than one of the heavychain isotypes $\mu, \gamma$ or $\alpha$ simultaneously [25]. The frequency of these B cells was markedly enhanced in patients with pSS compared with healthy controls. In particular, triple ( $\mu, \gamma$ and $\alpha$ chain transcript) positive $B$ cells were found only in patients with pSS. The expression of multiple Ig heavy-chain isotypes in individual peripheral $B$ cells occurs at the mRNA level but not at the protein level, because no multiple heavy-chainpositive $B$ cells could be detected by flow cytometric surface staining for their respective isotypes, $\lg M, \lg G$ and $\lg A$ [25]. Because these multiple-positive (class-switching) cells lacked mRNA expression of two GC B-cell markers, Bcl-6 and activation-induced cytidine deaminase [114], they most probably represent altered $\mathrm{CD} 27^{+}$memory $B$ cells but not GC B cells. Thus, no circulating $\mathrm{CD}^{2} 8^{++} \mathrm{IgD}^{-} \mathrm{GC} B$ cells have been detected in the peripheral blood by flow cytometric analysis, either in patients with pSS or in healthy controls [22].

These differences in the frequency of peripheral classswitching $\mathrm{CD} 27^{+} \mathrm{B}$ cells as well as the different imprints of 
somatic hypermutation between healthy controls and patients with pSS may reflect hyperactivation, altered differentiation and/or recirculation from secondary or ectopic (tertiary) lymphoid tissues of pSS B cells. Isotype class switching is a complex multistep process that requires close collaboration between surface IgM-expressing $B$ cells and $\mathrm{CD}^{+}{ }^{+}$helper T cells in the environment of secondary lymphoid tissues $[56,60]$, but it may also be induced by T-cell-independent pathways via Toll-like receptor engagement or BAFF-TACI interaction [90-92,103]. However, in both pathways, cellular collaboration depends on the binding and subsequent processing of antigen, interaction via complementary pairs of adhesion molecules, and a certain milieu of immunomodulatory cytokines, alterations of which may contribute to abnormalities in pSS $[59,60]$. One explanation for classswitching memory $B$ cells in the peripheral blood in pSS might be that they had incomplete differentiation processes, possibly in the ectopic (tertiary) lymphoid structures of the inflamed tissues. Thus, multiple lg transcript-positive (classswitching) $C D 27^{+} \mathrm{B}$ cells have been recently detected in focal minor (labial) salivary gland infiltrates of patients with pSS (A Hansen, K Reiter, K Kemnitz, PE Lipsky, T Dörner, unpublished work). These cells might therefore occur in the peripheral blood immediately after they switched and still had residual transcripts for pre-switch lg isotypes, thereby reflecting altered immune activation and/or incomplete differentiation processes. Abnormal expression of immunoregulatory Th2 cytokines, such as IL-2, IL-4 and IL-10 $[19,20,32,34,115]$, and local excess BAFF [53-55] may contribute to altered B-cell activation and class switching within the inflamed glands. It remains to be determined whether a molecular defect in metabolizing $\lg$ mRNA or enhanced B-cell turnover in pSS also contributes to the alterations in $\lg$ mRNA level.

\section{Conclusions}

Characteristic disturbances of peripheral B-cell homeostasis with depletion of $\mathrm{CD} 27^{+}$memory $\mathrm{B}$ cells in the peripheral blood and evidence for the accumulation and retention of antigen-experienced $B$ cells in the inflamed tissues, together with new findings on the role of chemokines and chemokine receptors, provide new insight into the immunopathogenesis of pSS. Although the present data indicate that there is no major molecular abnormality in generating the lgV heavychain and light-chain repertoire in patients with pSS, processes of chronic B-cell activation, disordered selection and differentiation apparently lead to remarkable differences in V gene usage by pSS B cells. Ectopically formed lymphoid structures within patients' inflamed tissues seem to be closely involved in these abnormalities. Selective influences after encountering (auto)antigen lead to preferential changes in $V_{L}$ gene usage and in the length of the CDR3 of $V_{H}$ rearrangements of glandular B cells in pSS. One possible explanation is that fine tuning of the antigen-binding pocket exerts a preferential influence on the $\mathrm{V}_{\mathrm{H}}$ CDR3 and $\lg \mathrm{V}_{\mathrm{L}}$ chains. Accumulation and disordered selection of (auto)antigen-
Figure 1

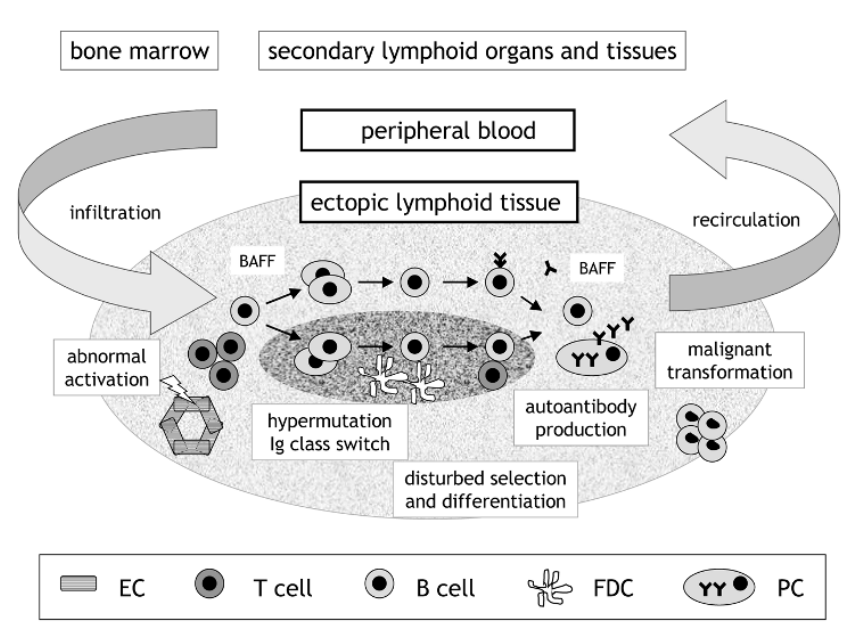

Hypothetical scheme of B-cell differentiation pathways in ectopic lymphoid tissues in primary Sjögren's syndrome. Preactivated peripheral $\mathrm{B}$ cells are recruited by chemokines into the microenvironment of chronically inflamed tissues. This microenvironment represents a 'niche' where $B$ cells may escape from peripheral check points against autoreactivity but are abnormally stimulated, proliferate and incompletely differentiate via T-cell-dependent or T-cell-independent pathways into memory B cells and plasma cells. Rheumatoid factor-expressing B cells may be abnormally stimulated by local BAFF excess and locally secreted (auto)antibodies. Abnormal stimulation and impaired censoring mechanisms enhance the risk for malignant transformation of B cells.

Emigration and recirculation of $B$ cells that had incomplete differentiation processes contribute to peripheral B-cell disturbances. EC, epithelial cell; FDC, follicular dendritic cell; PC, plasma cell; BAFF, B-cell activating factor; Ig, immunoglobulin.

experienced B cells in the 'niche' of ectopically formed lymphoid tissues may result in abnormal activation and differentiation of B cells, local autoantibody production, stimulation of RF-expressing $B$ cells and potential malignant transformation in pSS (Figure 1). Circulating peripheral $B$ cells from patients with pSS partly reflect these processes within the ectopic 'tertiary' and/or secondary lymphoid tissues. It is noteworthy that the combined results of recent studies indicate that detectable GC-like structures within these ectopic lymphoid tissues represent a progressive stage of disease or a higher degree of focal lymphoid sialadenitis in a subgroup of patients. However, GC-like structures seem not to be essential for B-cell disturbances in pSS. This is in line with the assumption that an important part of abnormal Bcell activation, selection and differentiation in pSS may be triggered by T-cell-independent pathways (Figure 1). Although these disturbances need further delineation, the available data may provide paths to understanding the underlying pathogenetic mechanisms of this entity. In particular, the awareness of the involvement of B cells in the immunopathology of pSS has aroused great interest in developing improved therapies, such as B-cell depletion by a chimeric anti-CD20 antibody [116] or B-cell modulation by an anti-CD22 antibody [117]. 


\section{Competing interests}

The authors declare that they have no competing interests.

\section{Acknowledgements}

This work was supported by Deutsche Forschungsgemeinschaft Grants Sonderforschungsbereich 421/B13 and Do 491/4-7.

\section{References}

1. Fox RI: Sjögren's syndrome. Lancet 2005, 366:321-331.

2. Kassan SS, Moutsopoulos HM: Clinical manifestations and early diagnosis of Sjögren syndrome. Arch Intern Med 2004, 164:1275-1284.

3. Hansen A, Lipsky PE, Dörner T: Immunopathogenesis of primary Sjögren's syndrome: implications for disease management and therapy. Curr Opin Rheum 2005, 17:558-565.

4. Mitsias DI, Kapsogeorgou EK, Moutsopoulos HM: The role of epithelial cells in the initiation and perpetuation of autoimmune lesions: lessons from Sjögren's syndrome (autoimmune epithelitis). Lupus 2006, 15:255-261.

5. Cisholm DM, Mason DK: Labial salivary gland biopsy in Sjögren's disease. J Clin Pathol 1968, 21:656-660.

6. Daniels TE: Labial salivary gland biopsy in Sjögren's syndrome. Assessment as a diagnostic criterion in 362 suspected cases. Arthritis Rheum 1984, 27:147-156.

7. Adamson TC, Fox RI, Frisman DM, Howell FV: Immmunohistologic analysis of lymphoid infiltrates in primary Sjögren's syndrome using monoclonal antibodies. J Immunol 1983, 130: 203-208.

8. Larsson A, Bredberg A, Henriksson G, Manthorpe R, Sallmyr A: Immunohistochemistry of the B-cell component in lower lip salivary glands of Sjögren's syndrome and healthy subjects. Scand J Immuno/ 2005, 61:98-107.

9. Xanthou G, Tapinos NI, Polihronis M, Nezis IP, Margaritis LH, Moutsopoulos HM: CD4 cytotoxic and dendritic cells in the immunopathologic lesion of Sjögren's syndrome. Clin Exp Immunol 1999, 118:154-163.

10. Zeher M, Adany R, Nagy G, Gomez R, Szegedi G: Macrophage containing factor XIII subunit a in salivary glands of patients with Sjögren's syndrome. J Invest Allergol Clin Immunol 1991, 1:261-265.

11. James JA, Harley JB, Scofield RH: Role of viruses in systemic lupus erythematosus and Sjögren's syndrome. Curr Opin Rheumatol 2001, 13:370-376.

12. Fox Rl, Pearson G, Vaughan JH: Detection of Epstein-Barr virus-associated antigens and DNA in salivary gland biopsies from patients with Sjögren's syndrome. J Immunol 1986, 137: 3162-3168.

13. Nakamura $H$, Kawakami A, Tominaga $M$, Hida A, Yamasaki $S$, Migita K, Kawabe Y, Nakamura T, Eguchi K: Relationship between Sjögren's syndrome and human T-Iymphotropic virus type I infection: follow-up study of $\mathbf{8 3}$ patients. J Lab Clin Med 2000, 135:139-144.

14. Triantafyllopoulou A, Tapinos N, Moutsopoulos HM: Evidence for Coxsackievirus infection in primary Sjögren's syndrome. Arthritis Rheum 2004, 50:2897-2902.

15. Bolstad Al, Jonsson R: Genetic aspects of Sjögren's syndrome. Arthritis Res 2002, 4:353-359.

16. Saegusa K, Ishimaru N, Yanagi K, Mishima K, Arakaki R, Suda T, Saito I, Hayashi Y: Prevention and induction of autoimmune exocrinopathy is dependent on pathogenic autoantigen cleavage in murine Sjögren's syndrome. $J$ Immunol 2002, 169: 1050-1057.

17. Nordmark G, Alm GV, Ronnblom L: Mechanisms of disease: primary Sjögren's syndrome and the type I interferon system. Nat Clin Pract Rheumatol 2006, 2:262-269.

18. Nagata $Y$, Inoue H, Yamada K, Higashiyama H, Mishima K, Kizu Y, Takeda I, Mizuno F, Hayashi Y, Saito I: Activation of Epstein-Barr virus by saliva from Sjögren's syndrome patients. Immunology 2004, 111:223-229.

19. Hagiwara E, Pando J, Ishigatsubo Y, Klinman DM: Altered frequency of type 1 cytokine secreting cells in the peripheral blood of patients with primary Sjögren's syndrome. J Rheumatol 1998, 25:89-93.

20. Mitsias DI, Tzioufas AG, Veiopoulou C, Zintzaras E, Tassios IK, Kogopoulou O, Moutsopoulos HM, Thyphronitis G: The Th1/Th2 cytokine balance changes with the progress of the immunopathological lesion of Sjögren's syndrome. Clin Exp Immunol 2002, 128:562-568.

21. Zintsaras E, Voulgarelis M, Moutsopoulos HM: The risk of lymphoma development in autoimmune diseases: a meta-analysis. Arch Intern Med 2005, 165:2337-2344.

22. Bohnhorst J, Bjorgan MB, Thoen JE, Natvig JB, Thompson KM: Bm1-bm5 classification of peripheral blood B cells reveals circulating germinal center founder cells in healthy individuals and disturbance in the $B$ cell subpopulations in patients with primary Sjögren's syndrome. J Immunol 2001, 167:3610-3618.

23. Bohnhorst JO, Bjorgan MB, Thoen JE, Jonsson R, Natvig JB, Thompson KM: Abnormal B cell differentiation in primary Sjögren's syndrome results in a depressed percentage of circulating memory B cells and elevated levels of soluble CD27 that correlate with serum IgG concentration. Clin Immunol 2002; 103:79-88.

24. Hansen A, Odendahl M, Reiter K, Jacobi AM, Feist E, Scholze J, Burmester GR, Lipsky PE, Dörner T: Diminished peripheral blood memory $B$ cells and accumulation of memory B cells in the salivary glands of patients with Sjögren's syndrome. Arthritis Rheum 2002, 46:2160-2167.

25. Hansen A, Gosemann M, Pruss A, Reiter K, Ruzickova S, Lipsky $\mathrm{PE}$, Dörner T: Abnormalities in peripheral $B$ cell memory of patients with primary Sjögren's syndrome. Arthritis Rheum 2004, 50:1897-1908.

26. Hansen A, Reiter K, Ziprian T, Jacobi A, Hoffmann A, Gosemann M, Scholze J, Lipsky PE, Dörner T: Dysregulation of chemokine receptor expression and function by $B$ cells of patients with primary Sjögren's syndrome. Arthritis Rheum 2005, 52:21092119.

27. Stott DI, Hiepe F, Hummel M, Steinhauser G, Berek C: Antigendriven clonal proliferation of $B$ cells within the target tissue of an autoimmune disease. The salivary glands of patients with Sjögren's syndrome. J Clin Invest 1998, 102:938-946.

28. Amft N, Curnow SJ, Scheel-Toellner D, Devadas A, Oates J, Crocker J, Hamburger J, Ainsworth J, Mathews J, Salmon M, et al.: Ectopic expression of the B cell-attracting chemokine BCA-1 (CXCL13) on endothelial cells and within lymphoid follicles contributes to the establishment of germinal center-like structures in Sjögren's syndrome. Arthritis Rheum 2001, 44: 2633-2641.

29. Xanthou G, Polihronis M, Tzioufas AG, Paikos S, Sideras P, Moutsopoulos HM: 'Lymphoid' chemokine messenger RNA expression by epithelial cells in the chronic inflammatory lesion of the salivary glands of Sjögren's syndrome patients. Possible participation in lymphoid structure formation. Arthritis Rheum 2001, 44:408-418.

30. Salomonsson $S$, Larsson $P$, Tengnér $P$, Mellquist $E$, Hjelmström $P$, Wahren-Herlenius $M$ : Expression of the $B$ cell-attracting chemokine CXCL13 in the target organ and autoantibody production in ectopic lymphoid tissue in the chronic inflammatory disease Sjögren's syndrome. Scand J Immuno/ 2002; 55: 336-342.

31. Barone F, Bombardieri M, Manzo A, Blades MC, Morgan PR, Challacombe SJ, Valesini G, Pitzalis C: Association of CXCL13 and CCL21 expression with the progressive organization of lymphoid-like structures in Sjögren's syndrome. Arthritis Rheum 2005, 52:1773-1784.

32. Salomonsson S, Jonsson MV, Skarstein K, Brokstad KA, Hjelmström $P$, Wahren-Herlenius $M$, Jonsson R: Cellular basis of ectopic germinal center formation and autoantibody production in the target organ of patients with Sjögren's syndrome. Arthritis Rheum 2003, 48:3187-3201.

33. Jonsson MV, Szodoray P, Jellestad S, Jonsson R, Skarstein K: Association between circulating levels of the novel TNF family members APRIL and BAFF and lymphoid organization in primary Sjögren's syndrome. J Clin Immuno/ 2005, 25:189-201.

34. Szodoray P, Alex P, Jonsson MV, Knowlton N, Dozmorov I, Nakken B, Delaleu N, Jonsson R, Centola M: Distinct profiles of Sjögren's syndrome patients with ectopic salivary gland germinal centers revealed by serum cytokines and BAFF. Clin Immunol 2005, 117:168-176.

35. Daridon C, Pers JO, Devauchelle V, Martins-Cavalho C, Hutin P, Pennec YL, Saraux A, Youinouh P: Identification of transitional type II B cells in the salivary glands of patients with primary Sjögren's syndrome. Arthritis Rheum 2006, 54:2280-2288. 
36. Schröder AE, Greiner A, Seyfert C, Berek C: Differentiation of B cells in the nonlymphoid tissue of the synovial membrane of patients with rheumatoid arthritis. Proc Natl Acad Sci USA 1996, 93:221-225

37. Hutloff A, Buchner K, Reiter K, Baelde HJ, Odendahl M, Jacobi A, Dörner T, Kroczek RA: Involvement of inducible costimulator in the exaggerated memory $B$ cell and plasma cell generation in systemic lupus erythematosus. Arthritis Rheum 2004, 50: 3211-3220.

38. Hsi ED, Singleton TP, Svoboda SM, Schnitzer B, Ross CW: Characterization of the lymphoid infiltrate in Hashimoto thyroiditis by immunohistochemistry and polymerase chain reaction for immunoglobulin heavy chain rearrangement. $A m ~ J$ Clin Pathol 1998, 110:327-333.

39. Ansell SM, Grant CS, Habermann TM: Primary thyroid lymphoma. Semin Oncol 1999, 26:316-323.

40. Kordossis T, Paikos S, Aroni K, Kitsanta P, Dimitrakopoulos A, Kavouklis E, Alevizou V, Kyriaki P, Skopouli FN, Moutsopoulos HM: Prevalence of Sjögren's-like syndrome in a cohort of HIV1-positive patients: descriptive pathology and immunopathology. Br J Rheumatol 1998; 37:691-695.

41. Widney D, Gundapp G, Said JW, van der Meijden M, Bonavida B, Demidem A, Trevisan C, Taylor J, Detels R, Martinez-Maza O: Aberrant expression of CD27 and soluble CD27 (sCD27) in HIV infection and in AIDS-associated lymphoma. Clin Immunol 1999, 93:114-123.

42. Scott CA, Avellini C, Desinan L, Pirisi M, Ferraccioli GF, Bardus P, Fabris C, Casatta L, Bartoli E, Beltrami CA: Chronic lymphocytic sialoadenitis in HCV-related chronic liver disease: comparison of Sjögren's syndrome. Histopathology 1997, 30:41-48.

43. Arcaini L, Burcheri S, Rossi A, Paulli M, Bruno R, Passamonti $F$, Brusamolino E, Molteni A, Pulsoni A, Cox MC, et al.: Prevalence of $\mathrm{HCV}$ infection in nongastric marginal zone B-cell lymphoma of MALT. Ann Oncol 2007, 18:346-350.

44. Maszzuccheli L, Blaser A, Kappeler A, Scharli P, Laissue JA, Baggiolini $\mathrm{M}$, Uguccioni $\mathrm{M}$ : $\mathrm{BCA}-1$ is highly expressed in Helicobacter pylori-induced mucosa-associated lymphoid tissue and gastric lymphoma. J Clin Invest 1999, 104:R49-R54.

45. Fox RI, Saito I: Criteria for diagnosis of Sjögren's syndrome. Rheum Dis Clin North Am 1994, 20:391-407.

46. Vitali C, Bombardieri S, Jonsson R, Moutsopoulos HM, Alexander EL, Carsons SE, Daniels TE, Fox PC, Fox RI, Kassan SS, et al. and the European Study Group on Classification Criteria for Sjögren's Syndrome: Classification criteria for Sjögren's syndrome: a revised version of the European criteria proposed by the American-European consensus group. Ann Rheum Dis 2002, 61:554-558.

47. Dawson LJ, Stanbury J, Venn N, Hasdimir B, Rogers SN, Smith PM: Antimuscarinic antibodies in primary Sjögren's syndrome reversibly inhibit the mechanism of fluid secretion by human submandibular salivary acinar cells. Arthritis Rheum 2006, 54: 1165-1173.

48. Jonsson MV, Delaleu N, Brokstad KA, Berggreen E, Skarstein K: Impaired salivary gland function in NOD mice: association with changes in cytokine profile but not with histopathologic changes in the salivary gland. Arthritis Rheum 2006, 54:23002305.

49. Tsunawaki S, Nakamura S, Ohyama $Y$, Sasaki M, Ikebe-Hiroki A, Hiraki A, Kadena T, Kawamura W, Shinohara M, Shirasuna K: Possible function of salivary gland epithelial cells as nonprofessional antigen-presenting cells in the development of Sjögren's syndrome. J Rheumato/ 2002, 29:1884-1896.

50. Vogelsang P, Jonsson MV, Dalvin ST, Appel S: Role of dendritic cells in Sjögren's syndrome. Scand J Immunol 2006, 64:219226.

51. Dimitrou ID, Kapsogeorgou EK, Moutsopoulos HM, Manoussakis $\mathrm{MN}$ : CD40 on salivary gland epithelial cells: high constitutive expression by cultured cells from Sjögren's syndrome patients indicating their intrinsic activation. Clin Exp Immunol 2002, 127:386-392.

52. Ohlsson M, Szodoray P, Loro LL, Johanessen AC, Jonsson R: CD40, CD154, Bax and Bcl-2 expression in Sjögren's syndrome salivary glands: a putative anti-apoptotic role during its effector phases. Scand J Immunol 2002, 56:561-571.

53. Groom J, Kalled SL, Cutler AH, Olson C, Woodcock SA, Schneider P, Tschopp J, Cachero TG, Batten M, Wheway J, et al:: Association of BAFF/BLyS overexpression and altered B cell differentiation with Sjögren's syndrome. J Clin Invest 2002, 109:59-68

54. Ittah M, Miceli-Richard C, Gottenberg JE, Lavie F, Lazure T, Ba N, Sellam J, Lepajolec C, Mariette X: B-cell activating factor of the tumor necrosis factor family (BAFF) is expressed under stimulation by interferon in salivary gland epithelial cells in primary Sjögren's syndrome. Arthritis Res Ther 2006, 8:R51.

55. Lavie F, Miceli-Richard C, Quillard J, Roux S, Leclerc P, Mariette $X$ : Expression of BAFF (BLys) in T cell infiltrating labial salivary glands from patients with Sjögren's syndrome. J Pathol 2004, 202:496-502

56. Kelsoe G: Life and death in germinal centers (Redux). Immunity 1996, 4:107-111.

57. Nanki T, Hayashida K, El-Gabalawy HS, Suson S, Shi K, Girschick HJ, Yavuz S, Lipsky PE: Stromal cell-derived factor-1-CXC chemokine receptor 4 interactions play a central role in CD4+ $\mathrm{T}$ cell accumulation in rheumatoid arthritis synovium. $J$ Immunol 2000, 165:6590-6598.

58. Shi K, Hayashida K, Kaneko M, Hashimoto J, Tomita T, Lipsky PE, Yoshikawa $\mathrm{H}$, Ochi T: Lymphoid chemokine B cell-attracting chemokine-1 (CXCL13) is expressed in germinal center of ectopic lymphoid follicles within the synovium of chronic arthritis patients. J Immunol 2001, 166:650-655.

59. Weyand CM, Kurtin PJ, Goronzy JJ: Ectopic lymphoid organogenesis. A fast track for autoimmunity. Am J Pathol 2001, 159: 787-793.

60. Cupedo T, Mebius RE: Role of chemokines in the development of secondary and tertiary lymphoid tissues. Semin Immunol 2003, 15:243-248.

61. Manthorpe R, Benoni C, Jacobsson L, Kirtava Z, Larsson A, Riedholm R, Nyhagen C, Tabery H, Theander E: Lower frequency of focal lip sialadenitis (focus score) in smoking patients. Can tobacco diminish the salivary gland involvement as judged by histological examination and anti-SSA/Ro and anti-SSB/La antibodies in Sjögren's syndrome? Ann Rheum Dis 2000, 59: 54-60.

62. Wise $\mathrm{CM}$, Woodruff RD: Minor salivary gland biopsies in patients investigated for primary Sjögren's syndrome. A review of 187 patients. J Rheumatol 1993, 20:1515-1518.

63. Hyjek E, Smith WJ, Isaacson PG: Primary B-cell Iymphoma of salivary glands and its relationship to myoepithelial sialadenitis. Hum Pathol 1988, 19:766-776.

64. Jaffe ES: Lymphoid lesions of the head and neck: a model of lymphocyte homing and lymphomagenesis. Mod Pathol 2002, 15:255-263.

65. Ioannidis JP, Vassiliou VA, Moutsopoulos HM: Long-term risk of mortality and lymphoproliferative disease and predictive classification of primary Sjögren's syndrome. Arthritis Rheum 2002, 46:741-747.

66. Xu KP, Katagiri S, Takeuchi T, Tsubota K: Biopsy of labial salivary glands and lacrimal glands in the diagnosis of Sjögren's syndrome. J Rheumatol 1997, 23:76-82.

67. Pijpe J, Kalk WW, van der Wal JE, Vissink A, Kluin PM, Roodenburg JL, Bootsma H, Kallenberg CG, Spijkervert FK: Parotid gland biopsy compared to labial biopsy in the diagnosis of patients with primary Sjögren's syndrome. Rheumatology, in press.

68. Dörner T, Lipsky PE: Abnormalities of B cell phenotype, immunoglobulin gene expression and the emergence of autoimmunity in Sjögren's syndrome. Arthritis Res 2002, 4: 360-371.

69. Potter KN, Mockridge Cl, Rahman A, Buchan S, Hamblin T, Davidson $B$, Isenberg DA, Stevenson FK: Disturbances in peripheral blood B cell subpopulations in autoimmune patients. Lupus 2002, 11:872-877.

70. Klein U, Rajewsky K, Küppers R: Human immunoglobulin $(\lg ) \mathrm{M}^{+} \lg \mathrm{D}^{+}$peripheral blood $\mathrm{B}$ cells expressing the CD27 cell surface antigen carry somatically mutated variable region genes: CD27 as a general marker for somatically mutated (memory) B cells. J Exp Med 1998, 188:1679-1689.

71. Agematsu K, Nagumo H, Yang FC, Nakazawa T, Fukushima K, Ito S, Sugita K, Mori T, Kobata T, Morimoto C: B cell subpopulations separated by CD27 and crucial collaboration of $C D 27^{+} B$ cells and helper T cells in immunoglobulin production. Eur $J$ Immunol 1997, 27:2073-2079.

72. Shinozaki K, Yasui K, Agematsu K: Direct B/B-cell interactions in immunoglobulin synthesis. Clin. Exp Immunol 2001, 124: 386-391. 
73. Nagumo H, Agematsu K, Kobayashi N, Shinozaki K, Hokibara S, Nagase H, Takamoto M, Yasui K, Sugane K, Komiyama A: The different process of class switching and somatic hypermutation; a novel analysis by CD27- naive B cells. Blood 2002, 99: 567-575.

74. Odendahl M, Mei H, Hoyer BF, Jacobi AM, Hansen A, Radbruch A, Dörner T: Generation of migratory antigen-specific plasma blasts and mobilization of resident plasma cells in a secondary immune response. Blood 2005, 105:1614-1621.

75. Odendahl M, Jacobi A, Hansen A, Feist E, Hiepe F, Burmester GR, Lipsky PE, Radbruch A, Dörner T: Disturbed peripheral B lymphocyte homeostasis in systemic lupus erythematosus. $J$ Immunol 2000, 165:5970-5979.

76. Jacobi AM, Odendahl M, Reiter K, Bruns A, Burmester GR, Radbruch A, Valet G, Lipsky PE, Dörner T: Correlation between circulating CD27 high plasma cells and disease activity in patients with systemic lupus erythematosus. Arthritis Rheum 2003, 48: $1332-1342$.

77. Mandl T, Bredberg A, Jacobsson LT, Manthorpe R, Henriksson G: CD4+ lymphopenia - a frequent finding in anti-SSA antibody seropositive patients with primary Sjögren's syndrome. J Rheumatol 2004, 31:726-728.

78. Gellrich S, Rutz S, Borkowski A, Golembowski S, Gromnica-lhle $\mathrm{E}$, Sterry W, Jahn S: Analysis of $\mathrm{V}_{\mathrm{H}}-\mathrm{D}-\mathrm{J}_{\mathrm{H}}$ gene transcripts in $B$ cells infiltrating the salivary glands and lymph node tissues of patients with Sjögren's syndrome. Arthritis Rheum 1999, 42: 240-247.

79. Hansen A, Jacobi A, Pruss A, Kaufmann O, Scholze J, Lipsky PE, Dörner $\mathrm{T}$ : Comparison of immunoglobulin heavy chain rearrangements between peripheral and glandular B cells in a patient with primary Sjögren's syndrome. Scand J Immunol 2003, 57:470-479.

80. Jacobi AM, Hansen A, Kaufmann O, Burmester GR, Lipsky PE, Dörner T: Analysis of immunglobulin light chain rearrangements in the salivary gland and blood of a patient with Sjögren's syndrome. Arthritis Res 2002, 4:R4.

81. Ansel KM, Ngo VN, Hyman PL, Luther SA, Forster R, Sedgwick JD, Browning JL, Lipp M, Cyster JG: A chemokine-driven feedback loop organizes lymphoid follicles. Nature 2000, 406:309314.

82. Dörner T, Lipsky PE: Signalling pathways in B cells: implications for autoimmunity. Curr Top Microbiol Immunol 2006, 305: 213-240.

83. Horsfall AC, Rose LM, Maini RN: Autoantibodiy synthesis in salivary glands of Sjögren's syndrome patients. J Autoimmun 1989, 2:554-568.

84. Berra A, Sterin-Borda L, Bacman S, Borda E: Role of salivary IgA in the pathogenesis of Sjögren syndrome. Clin Immunol 2002, 104:49-57

85. Rutjes SA, Utz PJ, van der Heijden A, Broekhuis C, van Venrooij WJ, Purin GJM: The La (SS-B) autoantigen, a key protein in RNA biogenesis, is dephosphorylated and cleaved early during apoptosis. Cell Death Differ 1999, 6:976-986.

86. Ohlsson M, Jonsson R, Brokstad KA: Subcellular redistribution and surface exposure of the Ro52, Ro60 and La48 autoantigens during apoptosis in human ductal epithelial cells: a possible mechanism in the pathogenesis of Sjögren's syndrome. Scand J Immuno/ 2002, 56:456-469.

87. Espinosa A, Zhou W, Ek M, Hedlund M, Brauner S, Popovic K, Horvath L, Wallerskog T, Mohamed O, Nyberg F, et al.: The Sjögren's syndrome-associated autoantigen Ro 52 is an E3 ligase that regulates proliferation and cell death. $J$ Immunol 2006, 176:6277-6285.

88. Namekawa T, Kuroda K, Kato T, Yamamoto K, Murata H, Sakamaki T, Nishioka K, Iwamoto I, Saitoh Y, Sumida T: Identification of Ro(SSA) $\mathbf{5 2} \mathrm{kDa}$ reactive $\mathrm{T}$ cells in labial salivary glands from patients with Sjögren's syndrome. J Rheumatol 1995, 22: 2092-2099.

89. Tengnér $\mathrm{P}$, Halse AK, Haga $\mathrm{HJ}$, Jonsson R, Wahren-Herlenius $\mathrm{M}$ : Detection of anti-Ro/SSA and anti-La/SSB autoantibody-producing cells in salivary glands from patients with Sjögren's syndrome. Arthritis Rheum 1998, 41:2238-2248.

90. Weller S, Faili A, Garcia C, Braun MC, Le Deist FF, de Saint Basile GG, Hermine O, Fischer A, Reynaud CA, Weill JC: CD40CD40L independent Ig gene hypermutation suggests a second B cell diversification pathway in humans. Proc Natl Acad Sci USA 2001, 98:1166-1170.
91. Obukhanych TV, Nussenzweig MC: T-independent type II immune responses generate memory $\mathbf{B}$ cells. J Exp Med 2006, 203:305-310.

92. Ng LG, Ng CH, Woehl B, Sutherland AP, Huo J, Xu S, Mackay F, Lam KP: BAFF costimulation of Toll-like receptor-activated B1 cells. Eur J Immunol 2006, 36:1837-1846.

93. Dörner T, Egerer K, Feist E, Burmester GR: Rheumatoid factor revisited. Curr Opin Rheumato/ 2004, 16:246-253.

94. Deacon EM, Matthews JB, Potts AJ, Hamburger J, Mageed RA, Jefferis R: Expression of rheumatoid factor associated crossreactive idiotypes by glandular B cells in Sjögren's syndrome. Clin Exp Immunol 1991, 83:280-285.

95. Kipps TJ, Tomhave E, Chen PP, Fox RI: Molecular characterization of a major autoantibody-associated cross-reactive idiotype in Sjögren's syndrome. J Immunol 1989, 142:4261-4268.

96. Miklos JA, Swerdlow SH, Bahler DW: Salivary gland mucosa associated lymphoid tissue lymphoma immunoglobulin VH genes show frequent use of V1-69 with distinctive CDR3 features. Blood 2000, 95:3878-3884.

97. Martin T, Weber JC, Levallois H, Labouret N, Soley A, Koenig S, Korganow AS, Pasquali JC: Salivary gland lymphomas in patients with Sjögren's syndrome may frequently develop from rheumatoid factor B cells. Arthritis Rheum 2000, 43:908916.

98. Hansen A Reiter $\mathrm{K}$, Pruss A, Loddenkemper C, Kaufmann $\mathrm{O}$, Jacobi AM, Scholze J, Lipsky PE, Dörner T: Dissemination of a Sjögren's syndrome-associated extranodal marginal-zone B cell lymphoma: circulating lymphoma cells and invariant mutational pattern of nodal Ig heavy and light chain variable-region gene rearrangements. Arthritis Rheum 2006, 54:127-137.

99. Tzioufas AG, Boumba DS, Skopouli FN, Moutsopoulos HM: Mixed monoclonal cryoglobulinemia and monoclonal rheumatoid factor cross-reactive idiotypes as predictive factors for the development of lymphoma in primary Sjögren's syndrome. Arthritis Rheum 1996, 39:767-772.

100. Voulgarelis M, Dafni UG, Isenberg DA, Moutsopoulos HM, and the members of the European Concerted Action on Sjögren's syndrome: Malignant lymphoma in primary Sjögren's syndrome. A multicenter, retrospective, clinical study by the European Concerted Action on Sjögren's syndrome. Arthritis Rheum 1999, 42:1765-1772.

101. Theander E, Manthorpe R, Jacobsson LTH: Mortality and causes of death in primary Sjögren's syndrome. A prospective cohort study. Arthritis Rheum 2004, 50:1262-1269.

102. Tsuiji M, Yurasov S, Velinzon K, Thomas S, Nussenzweig MC, Wardemann $\mathrm{H}$ : A checkpoint for autoreactivity in human $\operatorname{lgM}^{+}$ memory B cell development. J Exp Med 2006, 203:293-400.

103. Sutherland AP, Mackay F, Mackay CR: Targeting BAFF: immunomodulation for autoimmune diseases and lymphomas. Pharmacol Ther 2006, 112:774-786.

104. Martin F, Dixit VM: Unraveling TAClt functions. Nat Genet 2005, 37:793-794.

105. Szodoray $P$, Jellestad $S$, Alex $P$, Zhou T, Wilson PC, Centola M, Brun JG, Jonsson R: Programmed cell death of peripheral blood $B$ cells determined by laser scanning cytometry in Sjögren's syndrome with special emphasis on BAFF. J Clin Immunol 2004, 24:600-611.

106. Mariette X, Roux S, Zhang J, Bengoufa D, Lavie F, Zhou T, Kimberly R: The level of BLyS (BAFF) correlates with the titre of autoantibodies in human Sjögren's syndrome. Ann Rheum Dis 2003, 62:168-171.

107. Batten M, Fletcher C, Ng LG, Groom J, Wheway J, Laabi Y, Xin X, Schneider P, Tschopp J, Mackay GR, et al.: TNF deficiency fails to protect BAFF transgenic mice against autoimmunity and reveals a predisposition to B cell lymphoma. J Immunol 2004, 172:812-822.

108. Manoussakis MN, Tzioufas AG, Pange PJE, Moutsopoulos HM: Serologic profiles in subgroups of patients with Sjögren's syndrome. Scand J Rheumatol 1986, 61:89-92.

109. Radbruch A, Muehlinghaus G, Luger EO, Inamine A, Smith KG, Dörner T, Hiepe F: Competence and competition: the challenge of becoming a long-lived plasma cell. Nat Rev Immunol 2006, 6:741-750.

110. Wahren M, Skarstein K, Blange I, Petterson I, Jonsson R: MRL/Ipr mice produce anti-Ro 52,000 MW antibodies: detection, analysis of specificity and site of production. Immunology 1994, 83: 9-15. 
111. Heimbächer C, Hansen A, Pruss A, Jacobi A, Reiter K, Lipsky PE, Dörner $\mathrm{T}$ : Immunoglobulin $\mathrm{V} \times$ light chain analysis in patients with Sjögren's syndrome. Arthritis Rheum 2001, 44:626-637.

112. Kaschner S, Hansen A, Jacobi A, Reiter K, Monson NL, Odendahl M, Burmester GR, Lipsky PE, Dörner T: Immunoglobulin V $\lambda$ light chain gene usage in patients with Sjögren's syndrome. Arthritis Rheum 2001, 44:2620-2632.

113. Du M, Diss TC, Xu C, Peng H, Isaacson PG, Pan L: Ongoing mutation in MALT lymphoma immunoglobulin gene suggests that antigen stimulation plays a role in clonal expansion. Leukemia 1996, 10:1190-1197.

114. Muramatsu M, Kinoshita K, Fagarasan S, Yamada S, Shinkai $Y$, Honjo T: Class switch recombination and hypermutation require activation-induced cytidine deaminase (AID), a potential RNA editing enzyme. Cell 2000, 102:553-563.

115. Bertorello R, Cordone MP, Contini P, Rossi P, Indiveri F, Puppo F, Cordone G: Increased levels of interleukin-10 in saliva of Sjögren's syndrome patients. Correlation with disease activity. Clin Exp Med 2004, 4:148-151.

116. Steinfeld SD, Tant L, Burmester GR, Teoh NK, Wegener WA, Goldenberg DM, Pradier O: Epratuzumab (humanised antiCD22 antibody) in primary Sjögren's syndrome: an open-label phase I/II study. Arthritis Res Ther 2006, 8:R129.

117. Pijpe J, van Imhoff GW, Spijkervet FK, Roodenburg JL, Wolbink GJ, Mansour K, Vissink A, Kallenberg CG, Bootsma H: Rituximab treatment in patients with Sjögren's syndrome: an open-label phase II study. Arthritis Rheum 2005, 52:2740-2750. 